\title{
Theoretical Reflections on Practical and Heuristic Teaching Models in Professional Education of Higher Education
}

\author{
Xiaoqiu Jia ${ }^{1, a^{*}}$ and Xiaoyu Guan ${ }^{2, b}$
}

${ }^{1}$ School of tranffic \& transportation, Shijiazhuang Tiedao University, Shijiazhuang, China, 050043

${ }^{2}$ School of Material Science \& Engineering, Shijiazhuang Tiedao University, Shijiazhuang, Hebei, 050043

ajxq082@163.com, b guanxy021@163.com

*The corresponding author

Keywords: Practical teaching; Heuristic teaching; Cognitive process; Teaching design

\begin{abstract}
In the professional teaching of higher education, teachers must carry out heuristic teaching on the basic of the actual production and social living, which can results in the goal of improving the quality of specialized personnel training in the university. This paper discusses the epistemology of dialectical materialist epistemology and constructivist learning theory. Under the guidance of these two theories, this paper proposes the teaching principles about practice and heuristic teaching in the professional teaching of higher education, which is an effective teaching method for improving the quality of professional education in colleges.
\end{abstract}

\section{Introduction}

Heuristic teaching has been very popular, but there is no uniform definition, the model. The basic idea of heuristic teaching is, under the guidance of educators, the process of the students initiatively acquire knowledge, develop intelligence, cultivate individuality, and form perfect personality [1-3]. Its formation is the structure sequence of "inspired thinking - asking question and taste to solve explain question and exciting creating". In essence, in the teaching process, the teacher guides students to analyze actual problems which exist in social production and people life through some means, and consciously inspires them to think and solve problems, so as to enhance students' practical ability.

In addition, the practice model of teaching is carried out on the basic of the objective reality. It is based on social production and life taken as the content and background of teaching. This conforms to the actual needs of higher education whose purposes is to cultivate different specialized talents. In higher education, the truly meaningful teaching activities should be the perfect combination of professional practice and heuristic teaching. Professional practice teaching determines the content and purpose of teaching and heuristic teaching makes individuals build the internal cognitive structure and the formation of individual knowledge system [4-7].

This paper discusses the basic requirements of dialectical materialist epistemology and constructivist learning theory for professional education in higher education. On this basis, some principles of practical and heuristic teaching mode on professional education in higher education are discussed. These theoretical discussions are conducive to the higher education authorities and teachers to more clearly understand the teaching objectives, methods and basic requirements of professional education in higher education and scientific decision-making.

\section{The Main Point of View about the Dialectical Materialism Epistemology}

Basic point of view about dialectical materialism epistemology [8]:

The source of cognition: It is material to determine consciousness (feelings, thoughts, etc.), human consciousness is always the objective response of reality things when human knows of the world, regardless of both the subjective world and the objective world. 
Practice's effect on cognition: practice is the only source of cognition. Practice is the basis of cognition, the origin of cognition, the motivation of cognition deepening development and the only criterion of correcting problem.

The process of cognition: human cognition is deepening by the practice of the process. Simultaneously, human cognition can also, in turn, guide them in their next step of practice process. That people understand the nature of objective things is not done overnight. But this needs to repeatedly and continuously advancing process of awareness. This law requires people, as the host of awareness, should mobilize a variety of cognitive tools to actively participate in the process of understanding world.

\section{The Main Viewpoints of the Constructivist Learning Theory}

Constructivist learning theory emphasizes four key elements in the learning environment: "context creation", "coordination", "conversation" and "meaning construction". Specifically, there are the four characteristics of $[9,10]$ :

The Learning Process is the Cognitive Construction Process. In the learning process, learners use their existing cognitive structure to interact with the external environment. Thus, the external professional context perceived by the individual is very influential in his accepting new knowledge. The learner's learning efficiency is the highest and learning process will be shortened accordingly, only when the created external "professional context" is very close to or conducive to the new knowledge. On the contrary, if the external "professional context" is not conducive to learners to use the existing cognitive structure to internally represent the new knowledge, then the learning new knowledge will become very difficult or even possible damage to the existing knowledge system. In this sense, the "professional context" in instructional design must concern with whether or not learners are receptive to new knowledge.

The Learning Process is Self-Adjustment Process. The learning process is a very complex process. In the original cognitive structure of the learner, there are individual factors such as the mindset and the cognitive preference. So, different learners have different understanding from the same knowledge. Thus, in this sense, the constructivist learning theory holds that: the learning process is essentially the "adjustment" process between a learner's existing cognitive structure and new knowledge.

The assimilation process of cognitive structure means that the learner can successfully incorporate the new knowledge into his existing cognitive structure. The cognitive process of hue is that learners can not succeed in incorporating new knowledge into their existing cognitive structure, but will take the initiative to adjust the existing cognitive structure to accept new knowledge, so as to realize the cognitive of the balance. This ongoing "coordination" between the existing cognitive structures and the new knowledge runs through the learning process.

The Learning Result Lies in the "Conversation" with the Actual Life. The result of learning is the use of learned knowledge to solve real problems. This objective requirement makes it easier for learners to accept new knowledge in practice. That is to say, the knowledge acquired directly from practice is easier to be accepted by the individual, and the knowledge acquired through indirect way is more abstract and often appears disconnected with reality. The result of learning is the change of learners' behaviors and methods of dealing with something in practice. Therefore, it can promote learners' acceptance and use of new knowledge.

The Learner's Initiative. Constructivism also emphasizes the learner's initiative in the learning process. Learners have the intention to take the initiative to learn, and hope that by the learning process of new knowledge, they will re-modify their behavior in practice, methods in order to obtain the desired practice results. The result of this initiative is that learners gain individual experience and knowledge accumulation and their cognitive structure is more systematic and scientific. 


\section{The Practice and Heuristic Teaching Principles under the Guidance of the Dialectical Materialism Epistemology and Constructivism Learning Theory}

From a macro perspective, all human knowledge comes from practice and even indirectly acquired knowledge also ultimately comes from experience and knowledge accumulated from social production or living practice. At the same time, the knowledge acquired by learners content should be applied to practice and to withstand the test of practice. Then the professional practical and heuristic teaching of higher education under the guidance of dialectical materialist epistemology and constructivist learning theory should meet the following principles:

Teaching Content to Meet Needs of the Objective Practice. This is determined by the dialectical materialist epistemology. Teaching content must first meet the needs of social production and life. Once out of social practice, then the teaching content will not be easily understood by the students. Teaching inefficiency, poor teaching and other problems will appear so that teaching content will become a "castle in the air" and was shelved.

Teaching Methods Meets the "Coordination" Needs from the Cognitive Structure. In the process of cognition, teachers are required to help students construct their own knowledge systems so that they can fully understand and grasp the positive and negative aspects of new knowledge rather than be imposed by instructional content. When students take the initiative to understand the new knowledge, new experience is the time that they want to incorporate new knowledge, new experience into their existing cognitive structure. This is also the key to the construction of personal knowledge system, teachers should take the initiative to gradually guide students and improve their ability to use existing experience to build a personal knowledge system, which is more conducive to the absorption and grasping of knowledge.

Teaching "Professional Context" Should Meet the Need to Accept New Knowledge By Students. Teaching "professional context" of the design is not static. it needs to be continuously transformed, with the improvement of students' cognitive level and ability and the continuous improvement of cognitive structure. Constructivist learning theory holds that "context" is positively related to learning outcomes. Throughout the whole process of cognition, combined with the dialectical materialist epistemology, we can see that the situation of college teaching profession should be as close as possible to the professional reality and try to change with the change of students' cognitive structure.

\section{Summary}

In today's era of knowledge-based economy, cultivating high-end talents requires that the traditional teaching mode must be changed in higher education system, and the intensity of the practical and heuristic teaching reforming is constantly increased so as to meet talent needs of the social development.

\section{Acknowledgment}

The research about this title is sponsored by:

Reformation Project of Shijiazhuang Tiedao University Teaching Mode: Cultivating students' Comprehensive Professional Quality of Traffic \& Transportation Profession by "Practical Teaching" and "Heuristic Teaching" Mode;

Hebei Province Department of Education: The Research and Practice on Teaching Reformation of Higher Education in Hebei Province (2015GJJG094);

Education and Science Project in Twelfth Five of Shijiazhuang Tiedao University(Y201416).

\section{Reference}


[1] Li Yang and Yuexian Tao: The Evolvement and Development of Heuristic Teaching Mode, Journal of Sichuan Institution of Education (In Chinese), Vol. 20 (2004) No.1, p1.

[2] Yu Wu: Re-understanding of Heuristic Teaching, Chinese University Teaching (In Chinese), Vol. 10 (2011) No.1, p1.

[3] Mei Xiong: Research on Heuristic Teaching Principles (Higher Education Press (In Chinese), Beijing, 1998).

[4] Siyi Shen and Shicai Qin: Contemporary Teaching Method (China Materials Publishing House (In Chinese), Beijing, 1989).

[5] Xiaohui Chen: Instructional Dessign (Electronic Industry Press (In Chinese), Beijing, 2009).

[6] Hong Zhao: Research-oriented teaching and the reform of teaching methods in universities, Higher Education Research (In Chinese), Vol. 27 (2006) No.2, p71.

[7] Tao Zhu, Heng Ma and Qiang Liu: Research on Teaching Methods in the Case of Professional Technical Courses, Journal of Higher Education Research (In Chinese), Vol. 33 (2010) No.1, p91.

[8] Jiaxiang Qin: A Course in Marxist Philosophy (Peking University Press (In Chinese), Beijing, 2003).

[9] Shuxin Zheng and Guancheng Liang: Cognitive Science, Constructivism and Mathematics Teaching (Shanghai Education Press (In Chinese), Shanghai, 1998).

[10]Xiansui Kong: The Enlightenment of Constructivism to Teaching, Journal of Tsinghua University (Philosophy and Social Sciences) (In Chinese), Vol. 1 (2002), p128. 